\title{
Crescimento da bananeira Grande Naine submetida a diferentes lâminas de irrigação em tabuleiro costeiro
}

\author{
Jadson M. Oliveira', Mauricio A. Coelho Filho² \& Eugênio F. Coelho ${ }^{2}$
}

\begin{abstract}
RESUMO
Avaliou-se, com o presente trabalho, a influência de diferentes lâminas de irrigação sob o crescimento da cultura da bananeira Grande Naine. O experimento foi conduzido no campo experimental do Centro Nacional de Pesquisa Mandioca e Fruticultura. Utilizou-se delineamento experimental blocos casualizados com seis lâminas de irrigação e oito repetições. A lâmina de irrigação L1 correspondeu à chuva. A lâmina $\mathrm{L} 6$ foi determinada com o uso do Kc e ETo. As demais lâminas foram determinadas pela fórmula $\mathrm{NH}=\mathrm{Kx}$ AF x ETo, em que NH é a necessidade hídrica da cultura $\left(L\right.$ planta $\left.^{-1}\right), K$ (coeficiente empírico de transpiração da planta) e AF - área foliar $\left(\mathrm{m}^{2}\right.$ planta- $\left.^{-1}\right)$ e ETo - evapotranspiração de referência $(\mathrm{mm})$. Foram avaliados: altura da planta; circunferência do pseudocaule; área foliar; número de folhas vivas e duração do ciclo da cultura. O melhor crescimento da cultura foi obtido com o coeficiente de transpiração de 0,57 e uma lâmina de irrigação estimada em 1247 mm.
\end{abstract}

Palavras-chave: Musa spp., manejo de água, transpiração

\section{Growth of banana Grande Naine under different irrigation levels in Coastal Plain}

\begin{abstract}
This study evaluated the influence of different irrigation levels on the growth of the banana crop cv. Grande Naine. The experiment was conducted in the experimental field of the Centro Nacional de Pesquisa Mandioca e Fruticultura. A randomized block design was used with six levels of irrigation and eight replications. The irrigation L1 corresponded to rain. The irrigation L6 was determined using the Kc and ETo. The other irrigation levels were determined by the formula $\mathrm{NH}=\mathrm{K} \times \mathrm{AF} \times \mathrm{ETo}$, where $\mathrm{NH}$ is the water requirement of the crop ( $\left.\mathrm{L} \mathrm{plant}^{-1}\right), \mathrm{K}$ (empirical coefficient of plant transpiration), $\mathrm{AF}$ - leaf area $\left(\mathrm{m}^{2}\right.$ plant $\left.{ }^{-1}\right)$ and ETo - reference evapotranspiration $(\mathrm{mm})$. The parameters evaluated were: plant height, pseudostem circumference, leaf area, alive leaf number and duration of the crop cycle. The growth of cv. Grande Naine was influenced by irrigation, it is possible to estimate the water requirement of the banana crop, based on knowledge of leaf area and ETo. The best crop growth was obtained with a transpiration coefficient of 0.57 and irrigation depth estimated in $1247 \mathrm{~mm}$.
\end{abstract}

Key words: Musa spp., water management, transpiration

' Centro de Ciências Agrárias, Ambientais e Biológicas/UFRB, Campus Universitário, s/n Centro, CEP 44380-000, Cruz das Almas, BA. Fone: (75) 3621-2002. E-mail: jacojmo@hotmail.com

${ }^{2}$ Embrapa Mandioca e Fruticultura Tropical, Rua Embrapa, s/n, CP 07, CEP 44380 000, Cruz das Almas, BA. Fone: (75) 3621-8021. E-mail: mauricio.antonio.coelho@embrapa.br; ecoelho@cnpmf.embrapa.br 


\section{INTRODUÇÃO}

A bananeira é uma cultura originária do continente asiático cujo fruto se encontra entre os mais consumidos do mundo. As condições favoráveis ao seu cultivo são encontradas em regiões de latitude inferior a $30^{\circ}$ Norte ou Sul, em que a temperatura se situa entre os limites de 10 e $40^{\circ} \mathrm{C}$; entretanto, existe a possibilidade de seu cultivo em latitudes acima de $30^{\circ}$, desde que a temperatura não seja fator limitante, ou seja, média mínima abaixo de $11^{\circ} \mathrm{C}$ e/ou ocorrência de geadas ocasionais (Borges \& Souza, 2004).

No Brasil pode ser cultivada de Norte a Sul, tendo área plantada de 483,046 mil hectares e produção de 7.023.396 toneladas de banana. A maior parte da produção estava no nordeste do país, com 2.702 .683 toneladas (38,5\% do volume nacional). A Bahia se destaca como o maior produtor do nordeste e do Brasil, com 1.145.044 toneladas, 16,3\% da produção nacional.

A cultura da bananeira é exigente em água e seu crescimento e produtividade tendem a aumentar linearmente com a transpiração que, por sua vez, depende da disponibilidade de água no solo passível de ser controlada pela irrigação (Coelho et al., 2006a). O desenvolvimento da cultura está à mercê das condições meteorológicas locais, onde se tem menor ou maior taxa de evapotranspiração e, em consequência, menor ou maior fluxo de seiva e de fotoassimilados.

A redução do crescimento das plantas decorre da redução da área foliar e da condutância estomática, limitando a taxa fotossintética. Visando à obtenção de colheitas economicamente rentáveis, considera-se suficiente uma precipitação mensal entre 100 e $180 \mathrm{~mm}$ mês $^{-1}$ (Costa et al., 2009). O crescimento e o rendimento da cultura são afetados pelo déficit hídrico (Doorenbos \& Kassam, 1994). Uma das primeiras reações da planta ao déficit hídrico é a diminuição da turgescência $\mathrm{e}$, associado à diminuição do processo de crescimento, em particular, o crescimento em expansão (Taiz \& Zeiger, 2009).

Neste sentido avaliou-se, a influência de diferentes lâminas de irrigação sob o crescimento da cultura da bananeira 'Grande Naine'.

\section{Material e MÉtodos}

O experimento foi conduzido em campo experimental do Centro Nacional de Pesquisa Mandioca e Fruticultura (CNPMF/ EMBRAPA) localizado no município de Cruz das Almas, BA ( $\left(12^{\circ} 48^{\prime} \mathrm{S} ; 3^{\circ} 06^{\prime} \mathrm{W}\right.$ e $225 \mathrm{~m}$ de altitude). O clima da região é classificado como úmido a subúmido, com pluviosidade média anual de $1.143 \mathrm{~mm}$ (D'Angiolella et al., 2000). De acordo com a classificação de Köppen, enquadra-se no tipo Aw a Am, tropical quente e úmido.

A cultura foi cultivada em Latossolo Amarelo álico (Souza \& Souza, 2001) de textura média contendo $669 \mathrm{~g}$ de areia $\mathrm{kg}^{-1}$,

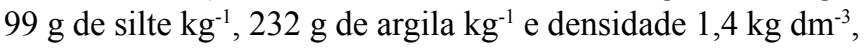
A umidade do solo correspondente à capacidade de campo é $0,35 \mathrm{~m} \mathrm{~m}^{-3}$ equivalente à tensão de $-10 \mathrm{kPa}$ e a umidade no ponto de murchamento é de $0,18 \mathrm{~m}^{3} \mathrm{~m}^{-3}$ equivalente a uma tensão $-1500 \mathrm{kPa}$. A análise química do solo evidenciou, para as camadas de $0-0,20 \mathrm{~m}$ e $0,20-0,40 \mathrm{~m}$, respectivamente, os seguintes valores: $\mathrm{pH}$ em água $=6,4$ e 5,$4 ; \mathrm{P}\left(\mathrm{mg} \mathrm{dm}^{-3}\right)=$ 72 e $29 ; \mathrm{K}\left(\mathrm{cmol}_{\mathrm{c}} \mathrm{dm}^{-3}\right)=0,17$ e 0,$11 ; \mathrm{Ca}\left(\mathrm{cmol}_{\mathrm{c}} \mathrm{dm}^{-3}\right)=2,6 \mathrm{e}$ 1,$7 ; \mathrm{Mg}\left(\mathrm{cmol}_{\mathrm{c}} \mathrm{dm}^{-3}\right) 1,1$ e 0,$8 ; \mathrm{Al}\left(\mathrm{cmol}_{\mathrm{c}} \mathrm{dm}^{-3}\right)=0,0$ e 0,$0 ; \mathrm{Na}$ $\left(\mathrm{cmol}_{\mathrm{c}} \mathrm{dm}^{-3}\right)=0,04$ e 0,$05 ; \mathrm{H}+\mathrm{Al}\left(\mathrm{cmol}_{\mathrm{c}} \mathrm{dm}^{-3}\right)=1,65$ e 2,31 ; $\mathrm{S}\left(\mathrm{cmol}_{\mathrm{c}} \mathrm{dm}^{-3}\right)=3,91$ e 2,66 ; CTC $\left(\mathrm{cmol}_{\mathrm{c}} \mathrm{dm}^{-3}\right)=5,56$ e 4,97 .

A cv. Grande Naine foi cultivada com espaçamento $2 \mathrm{~m}$ entre plantas e 2,5 m entre fileiras com cinco plantas úteis por parcela experimental, ocupando uma área útil de $25 \mathrm{~m}^{2}$. O sistema de irrigação utilizado foi o gotejamento com quatro gotejadores por planta, com vazão nominal de $4 \mathrm{~L} \mathrm{~h}^{-1}$, por emissor. O delineamento experimental utilizado foi em blocos casualizados com seis lâminas de irrigação e oito repetições.

O manejo da irrigação foi o que diferenciou as lâminas de água; desta forma, a necessidade hídrica da cultura foi estimada com base em modelo de estimativa de transpiração $(\mathrm{T}=\mathrm{K}$ x AF x ETo; L planta ${ }^{-1}$ ) segundo Coelho Filho et al. (2004; 2007). Como não possuíamos estudos com bananeira foram testados diferentes niveis de $\mathrm{K}$, resultando na fórmula $\mathrm{NH}=\mathrm{K} x \mathrm{AF} x$ ETo sendo NH a necessidade hídrica da cultura $\left(\mathrm{L} \mathrm{planta}^{-1}\right), \mathrm{AF}$ a área foliar $\left(\mathrm{m}^{2}\right)$, ETo evapotranspiração de referência $(\mathrm{mm})$ e $\mathrm{K}$ o coeficiente de transpiração que variou de 0 (zero) para a lâmina $\mathrm{L} 1 ; 0,18$ para a lâmina $\mathrm{L} 2 ; 0,37$ para a lâmina L3; 0,56 para a lâmina L4 e 0,74 para a lâmina L5. Esses valores selecionados estão acima e abaixo dos valores de modelos de estimativas de transpiração máxima de diferentes culturas. Os valores de área foliar utilizados na estimativa da necessidade hídrica da cultura foram resultantes da maior área foliar detectada entre as plantas de maior crescimento. A lâmina L6 foi determinada tomando-se como base a evapotranspiração de referência (ETo) e os valores de coeficientes da cultura (Kc), recomendados por Doorenbos \& Kassam (1994). Os valores de $(\mathrm{Kc})$ adotados para a cultura da banana, cv. Grande Naine foram: 0,4 (<60 dias após plantio, DAP); 0,45 (60 - 90 DAP); 0,5 (90 - 120 DAP); 0,6 (120 - 150 DAP); 0,7 (150 - 180 DAP); 0,85 (180 - 210 DAP); 1,0 (210 - 240 DAP); 1,1 (240 - 300 DAP); 1,0 (300 - 330 DAP); 0,8 (330 - 390 DAP) e 1,1 (após 390 DAP). Todos os tratamentos foram igualmente irrigados até os 110 DAP com base no coeficiente da cultura $(\mathrm{Kc})$ e evapotranspiração de referência (ETo); a partir do $111^{\circ}$ dia houve diferenciação entre os tratamentos.

O momento da irrigação foi determinado com base no potencial de água no solo monitorado por tensiômetros, instalados na área experimental. As irrigações só foram realizadas quando os tensiômetros instalados no tratamento L5, tomado como referência, atingiram valores absolutos superiores a $15 \mathrm{kPa}$, ou seja, quando o potencial de água no solo estava abaixo de $-15 \mathrm{kPa}$. Os tensiômetros foram instalados a $0,40 \mathrm{~m}$ da planta em 0,30 e $0,60 \mathrm{~m}$ de profundidade.

Os dados da evapotranspiração potencial diária foram estimados pela fórmula de Penman-Monteith modificada (Allen et al., 1998) a partir de dados climáticos obtidos de uma estação agrometeorológica automática, instalada a $200 \mathrm{~m}$ da área experimental.

As adubações de fundação e cobertura foram feitas de acordo com a recomendação de Borges \& Souza (2004).

As variáveis de crescimento avaliadas mensalmente foram: altura da planta até a inserção da terceira folha (Alt), 
circunferência do pseudocaule (Circ) a 0,30 m da superfície do solo, área foliar total (AF) por planta e número de folhas vivas (NF). Foram consideradas folhas vivas aquelas com mais de $50 \%$ de área verde. A área foliar foi estimada a partir da leitura do comprimento e da largura da terceira folha usando a fórmula proposta por Alves et al. (2001) Eq. (1). Também foi analisada a duração do ciclo da cultura, em dias, do plantio até a floração; da floração até a colheita e do plantio até a colheita.

$$
\mathrm{AF}=0,5789 \times \mathrm{C} \times \mathrm{L} \times \mathrm{NF}
$$

em que:

$$
\begin{array}{ll}
\mathrm{AF} & \text { - área foliar total, } \mathrm{m}^{2} \\
\mathrm{C} & \text { - comprimento da terceira folha, } \mathrm{m} \\
\mathrm{L} & \text { - largura máxima da terceira folha, } \mathrm{m} \\
\mathrm{NF} & \text { - número de folhas da planta }
\end{array}
$$

Os dados de crescimento foram submetidos à análise de variância e regressão utilizando-se o software SISVAR ${ }^{\circledR}$ (Ferreira, 2008).

\section{Resultados E Discussẽo}

$\mathrm{Na}$ avaliação realizada aos quatro meses após o plantio não se verificou qualquer efeito significativo dos manejos de irrigação para as variáveis estudadas (Tabela 1). Este comportamento se deve ao fato da diferenciação dos manejos de irrigação ocorrer somente depois do terceiro mês após o plantio tendo em vista que antes deste período a demanda hídrica da cultura foi suprida pela precipitação pluviométrica. Da mesma maneira, Braga Filho et al. (2008) não encontraram, avaliando diferentes lâminas de irrigação na cultura da bananeira, efeito

A.

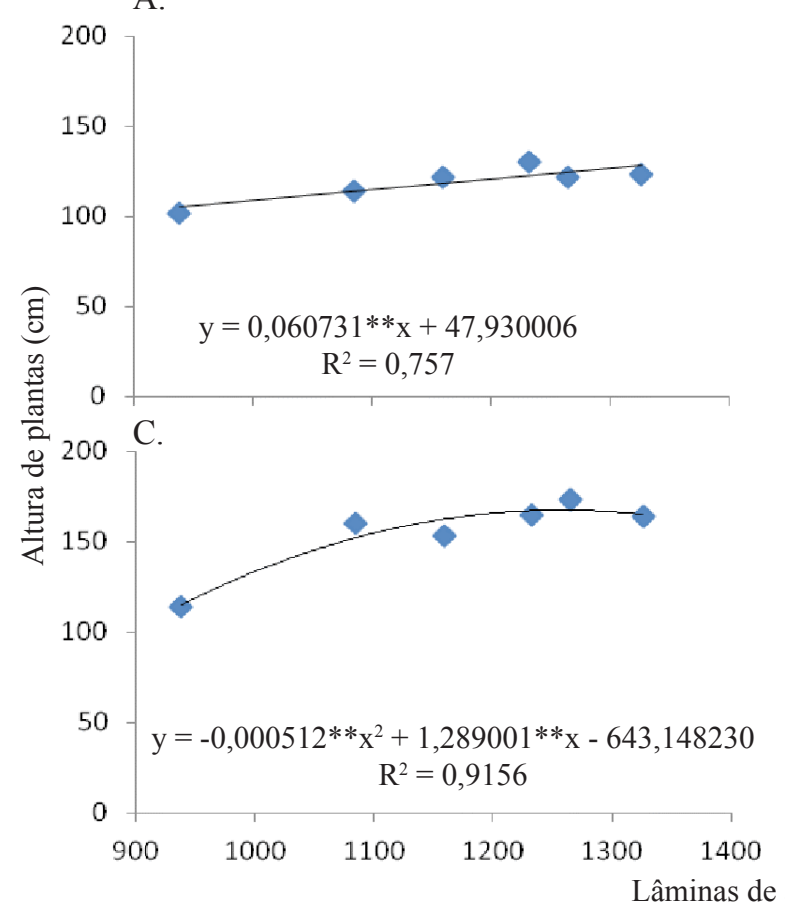

Lâminas de água (mm)
Tabela 1. Resumo da análise de variância e teste $\mathrm{F}$ da altura de plantas (Alt), da circunferência do pseudocaule a 0,30 $\mathrm{m}$ da superfície do solo (Circ), do

\begin{tabular}{|c|c|c|c|c|}
\hline FV & Alt & Circ. & NF & $\overline{A F}$ \\
\hline & \multicolumn{4}{|c|}{4 meses } \\
\hline Blocos & $0,77^{\mathrm{ns}}$ & $1,12^{\text {ns }}$ & $1,66^{\mathrm{ns}}$ & $0,19^{\text {ns }}$ \\
\hline Lâminas & $1,09^{\text {ns }}$ & $2,12^{\text {ns }}$ & $0,67^{\text {ns }}$ & $1,17^{\text {ns }}$ \\
\hline CV (\%) & 12,56 & 11,07 & 5,28 & 24,34 \\
\hline \multirow[t]{2}{*}{ Média } & 80 & 32,02 & 12,27 & 2,45 \\
\hline & \multicolumn{4}{|c|}{6 meses } \\
\hline Blocos & $2,75^{\star}$ & $2,71^{*}$ & $7,04 * *$ & 6,04 ** \\
\hline Lâminas & $4,48^{* *}$ & $6,00 * \star$ & $12,55^{\star *}$ & $6,41 * *$ \\
\hline CV (\%) & 11 & 9,7 & 14,36 & 25,1 \\
\hline \multirow[t]{2}{*}{ Média } & 118,83 & 43,81 & 10,45 & 4,5 \\
\hline & \multicolumn{4}{|c|}{8 meses } \\
\hline Blocos & $1,22^{\text {ns }}$ & $3,26^{\star *}$ & $6,11^{\star *}$ & $4,99 * *$ \\
\hline Lâminas & $18,10^{\star *}$ & $30,23^{\star *}$ & $22,04^{\star \star}$ & $28,73^{\star *}$ \\
\hline CV $(\%)$ & 10,69 & 7,91 & 12,33 & 18,39 \\
\hline \multirow[t]{2}{*}{ Média' } & 146,08 & 51,71 & 11,2 & 6,93 \\
\hline & \multicolumn{4}{|c|}{10 meses } \\
\hline Blocos & $0,82^{\text {ns }}$ & $1,78^{\text {ns }}$ & $0,98^{\text {ns }}$ & $1,35^{\text {ns }}$ \\
\hline Lâminas & $28,18^{* \star}$ & $34,62^{* *}$ & $5,05^{\star *}$ & 24,91 ** \\
\hline CV (\%) & 7,3 & 6,19 & 13,27 & 16,56 \\
\hline Média & 154,88 & 54,75 & 12,15 & 7,45 \\
\hline
\end{tabular}
número de folhas vivas (NF) e da área foliar planta-1 (AF) da cv. Grande Naine submetida a seis lâminas de irrigação, aos quatro, seis, oito e dez meses após o plantio, no primeiro ciclo produtivo

CV - coeficiente de variação

significativo das lâminas nas características de crescimento aos quatro meses após o plantio.

A altura máxima de plantas foi atingida aos dez meses após o plantio (Figura 1C) com um crescimento acentuado na altura da planta entre as lâminas de irrigação L1 $\left(938 \mathrm{~mm}\right.$ ciclo $\left.^{-1}\right) \mathrm{e}$

B.

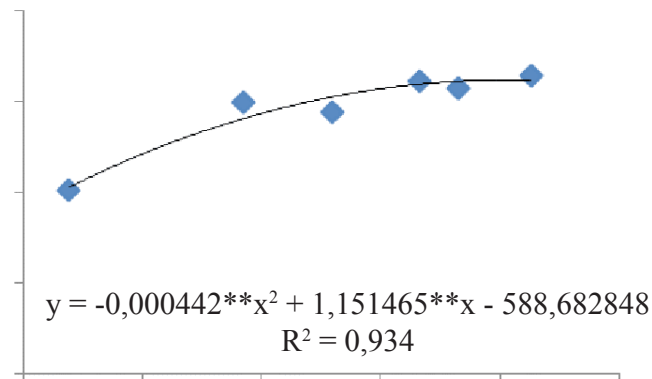

D.

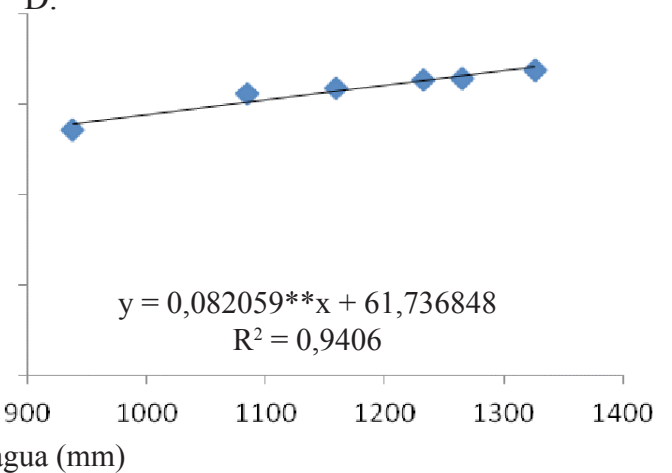

** significativo a 0,01 de probabilidade, para toda a equação

Figura 1. Altura de plantas em função das lâminas de água aos seis meses (A), oito meses (B), dez meses (C) e na colheita (D) de bananeira Grande Naine 
L2 (1085 $\left.\mathrm{mm} \mathrm{ciclo}^{-1}\right)$; este, por sua vez, se assemelhou aos resultados obtidos com os manejos L3, L4, L5 e L6 (1159, 1232,1326 e $1265 \mathrm{~mm} \mathrm{ciclo}^{-1}$ respectivamente); no entanto, a análise de regressão entre a altura de plantas e a lâmina de água aplicada mostrou que a maior altura de planta $(1,87 \mathrm{~m})$ seria obtida com uma lâmina de água estimada em $1289 \mathrm{~mm} \mathrm{ciclo}^{-1}$. Quando se analisou a regressão da altura de plantas em função dos diferentes coeficientes " $\mathrm{K}$ ", utilizados no cálculo da lâmina de água, obteve-se um valor máximo de altura de plantas com coeficiente de 0,55 (Figura 2).

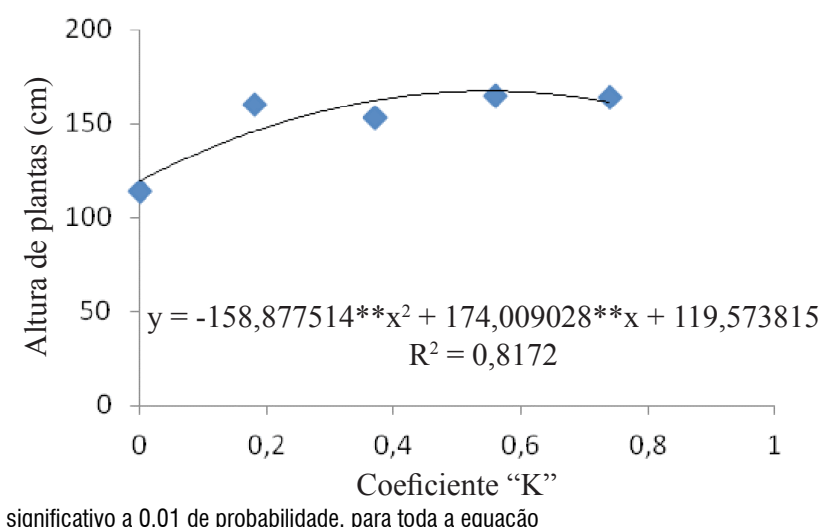

Figura 2. Altura máxima de plantas em função dos coeficientes de transpiração "K" de bananeira Grande Naine

$\mathrm{O}$ resultado encontrado para altura de plantas no presente estudo está de acordo com os obtidos por Alves et al. (2010) que encontraram altura máxima de $1,89 \mathrm{~m}$ avaliando diferentes combinações de duas fontes nitrogenadas, amoniacal e nítrica, aplicadas por fertirrigação sobre o crescimento e produtividade

A.

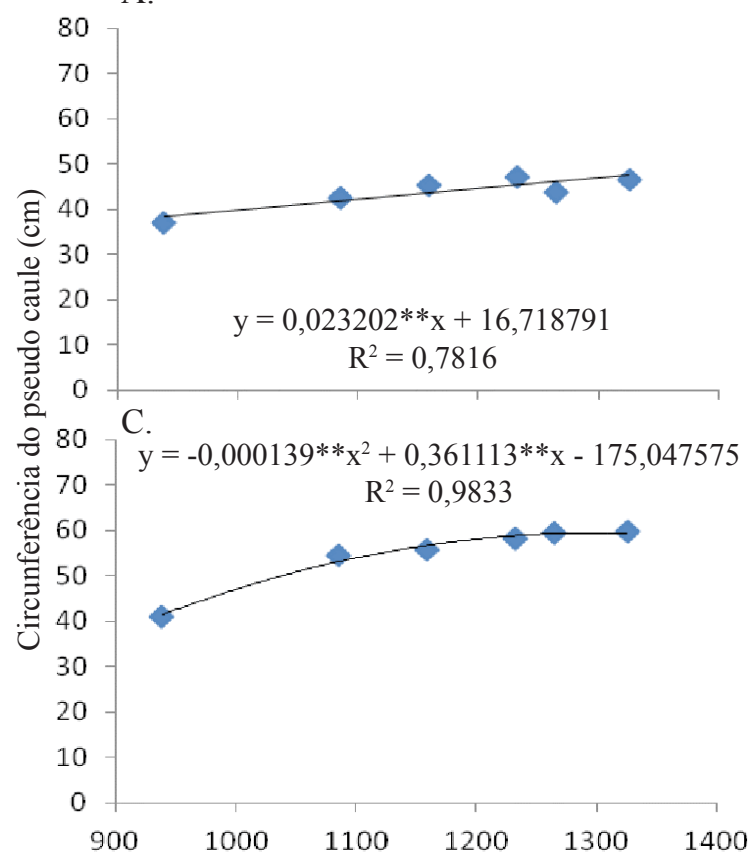

da bananeira Grande Naine nos $1^{\circ}$ e $2^{\circ}$ ciclos de produção. Por outro lado, este resultado difere do encontrado por Leite et al. (2003) ou seja, valores de 2,56 m para esta variável, trabalhando com a mesma cultivar na região sul da Bahia. Silva et al. (2003) avaliaram genótipos de bananeira em locais produtores de banana, Lavras, Viçosa e Jaíba, MG, Cruz das Almas e Guanambi, BA, e obtiveram os seguintes valores de altura das plantas para a cv. Grande Naine: 1,$95 ; 2,05 ; 2,18 ; 1,78$ e 2,33 m, respectivamente, valores esses próximos aos encontrados no presente trabalho. $\mathrm{O}$ ajuste de diferentes modelos matemáticos, polinomial aos oito e dez meses e linear na colheita, descritos na Figura 1, pode ser justificado pelo fato de ocorrerem precipitações pluviométricas em períodos que antecederam o período da colheita influenciando um crescimento maior das plantas que receberam menor quantidade de água durante o ciclo produtivo.

Foram obtidos modelos matemáticos, a partir da análise de regressão da circunferência do pseudocaule em função das lâminas de água aplicadas, verificando-se ajustes de modelos lineares aos seis meses após o plantio e na colheita, e quadráticos aos oito e dez meses após o plantio como os de maior representatividade do comportamento da variável (Figura 3). As precipitações pluviométricas registradas no período entre o oitavo e o décimo mês após o plantio (260 aos 300 dias após o plantio) influenciaram no aumento da circunferência do pseudocaule das plantas que receberam menor quantidade de água, o que justifica o fato do ajuste de modelos matemáticos passarem de quadrático aos oito e dez meses, para linear, na colheita.

A análise de regressão demonstrou que o valor máximo de circunferência do pseudocaule $(0,59 \mathrm{~m})$ foi obtido com uma lâmina de água estimada em $1298 \mathrm{~mm} \mathrm{ciclo}^{-1} \mathrm{e}$ atingido aos dez meses após o plantio (Figura 3C); enfim, o coeficiente " $\mathrm{K}$ "

B.

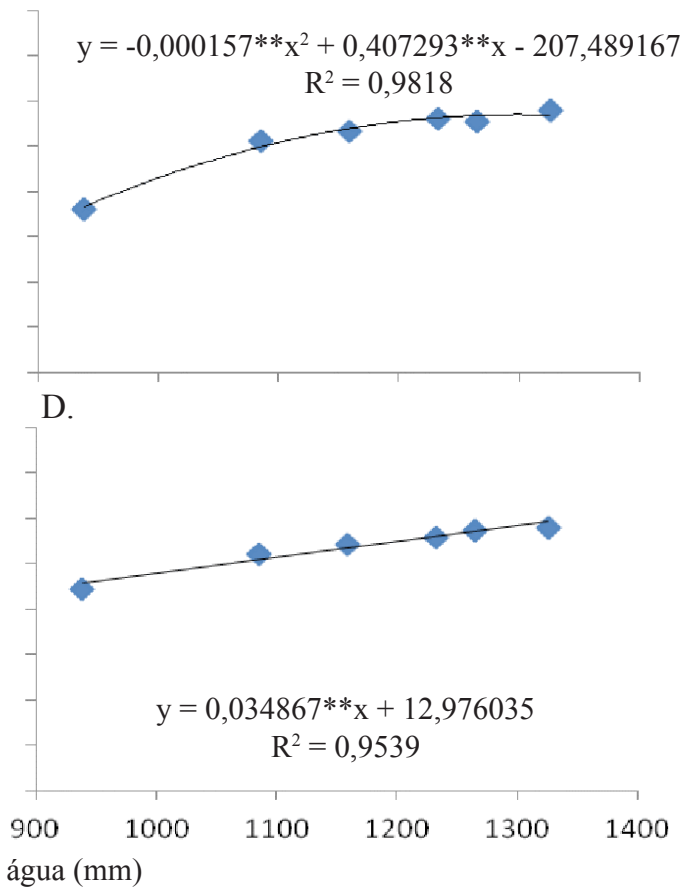

** significativo a 0,01 de probabilidade, para toda a equação

Lâminas de água ( $\mathrm{mm})$

Figura 3. Circunferência do pseudocaule da cv. de bananeira Grande Naine em função das lâminas de água aos seis, (A), oito (B) e dez meses após o plantio (C) e na colheita (D) 
responsável pelo maior valor da variável foi estimado em 0,60 (Figura 4).

Silva et al. (2004) encontraram, estudando três cvs. de bananeira, Grande Naine, FHIA 18 e Prata, efeito significativo das lâminas de água ao 0,01 de probabilidade resultando num comportamento linear apenas para a cultivar FHIA 18. Ramos et al. (2009) obtiveram, estudando o desempenho de 13 cultivares, uma circunferência máxima de $0,76 \mathrm{~m}$ para a cultivar Grande Naine; a diferença entre o resultado encontrado pelo último autor e o deste trabalho, é de apenas $0,17 \mathrm{~m}$ na medida da circunferência do pseudocaule e só $0,05 \mathrm{~m}$ na medida do seu diâmetro, sinalizando pequenas diferenças numéricas entre tais resultados.

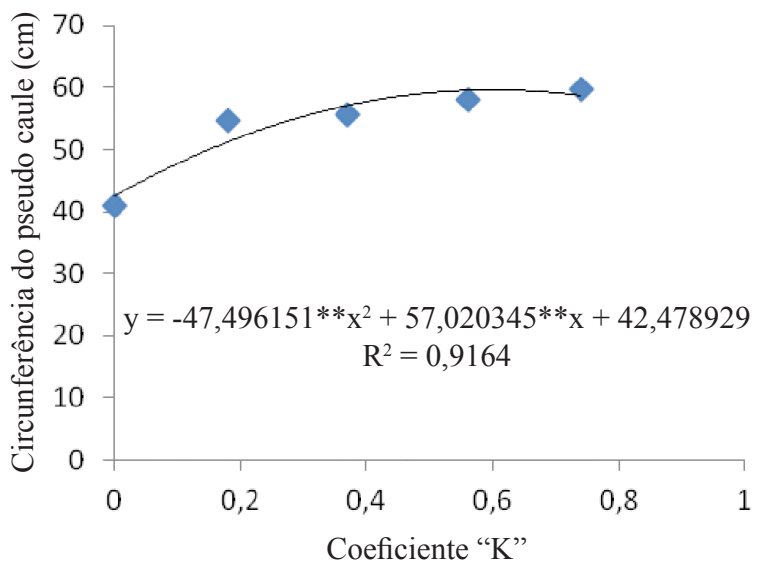

** significativo a 0,01 de probabilidade, para toda a equação

Figura 4. Circunferência do pseudocaule em função dos coeficientes de transpiração, da bananeira Grande Naine

A.

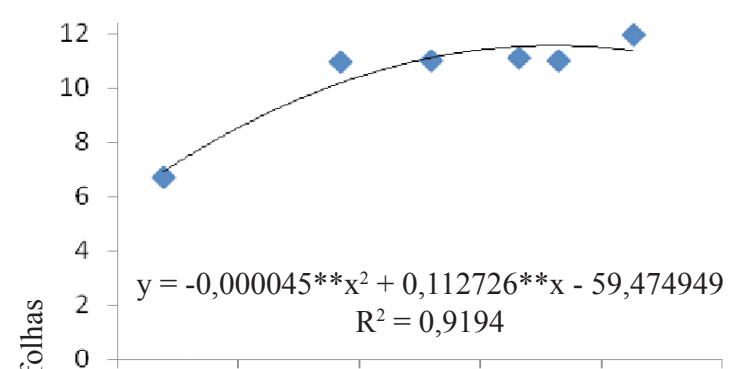

C.

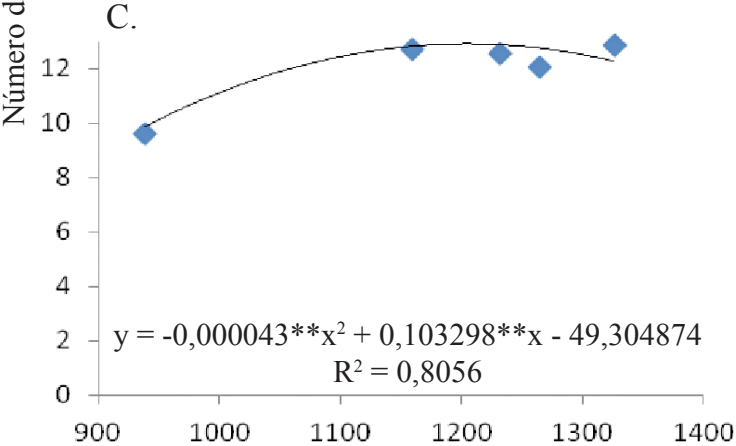

O número máximo de folhas vivas foi atingido aos dez meses após o plantio, variando entre 10 , para o tratamento L1 $\left(938 \mathrm{~mm} \mathrm{ciclo}^{-1}\right), 12$ para o L6 (1265 mm ciclo $\left.{ }^{-1}\right)$ e 13 folhas, para os tratamentos L2, L3, L4 e L5 (1085, 1159, 1232 e 1326 mm ciclo ${ }^{-1}$, respectivamente) (Figura 5). Segundo Rodrigues et al. (2009) para bananas do subgrupo Cavendish há resultados que indicam os valores de oito a nove como sendo o mínimo de folhas no momento da floração, necessário para o bom desenvolvimento da planta.

No momento da colheita a análise de variância não detectou efeito significativo das lâminas de irrigação para o número de folhas vivas devido ao fato de não haver emissão nem crescimento de folha após a floração ocorrendo, após este período, queda natural de folhas e desfolhas realizadas para controlar a infestação da Sigatoka-amarela, aproximando ou mesmo igualando a quantidade de folhas vivas entre as plantas.

O número de folhas vivas é um parâmetro importante a ser analisado tendo em vista que a taxa de fotossíntese depende da área foliar da planta. A redução do número de folhas da floração até a colheita se deve, sobretudo, à translocação de fotoassimilados para a formação de frutos que passam a ser o dreno preferencial da planta levando à senescência natural das folhas e à presença de Sigatoka-amarela (Silva et al., 2006).

Donato et al. (2006) relataram, em Guanambi, BA, que a cv. Grande Naine apresentou um número máximo de 13 folhas. Andrade et al. (2002) notaram, em Teresina, PI, 14 folhas para cv. Grande Naine e 13 para os cvs Nanicão e Caipira. Segundo Silva et al. (2000) no sequeiro, em Cruz das Almas, BA, a mesma cultivar apresentou 11 folhas; os resultados deste trabalho estão muito próximos dos relatados pelos autores supracitados.

B.

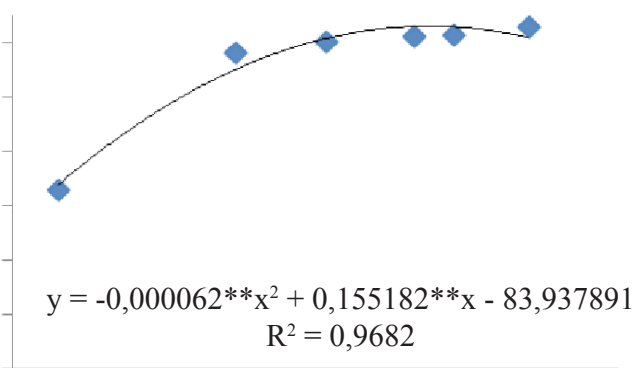

D.

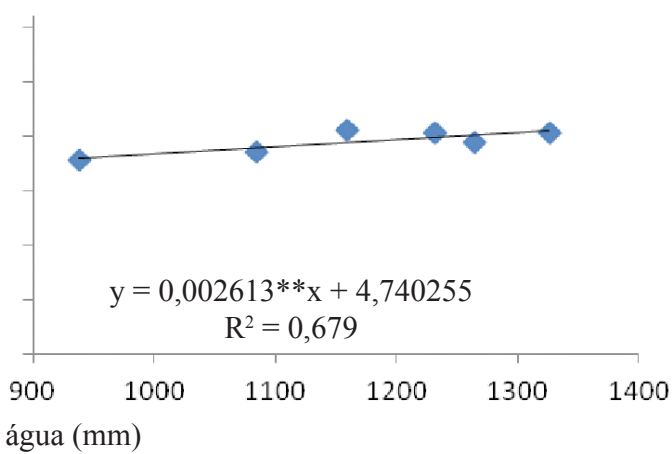

* $e$ ** significativo a 0,05 e 0,01 de probabilidade, para toda a equação

Lâminas de água (mm)

Figura 5. Número de folhas vivas da cv. de bananeira Grande Naine em função das lâminas de água aos seis, (A), oito (B) e dez meses após o plantio (C) e na colheita (D) 
A análise de regressão demonstrou que o número máximo de folhas $(13,2)$ foi obtido com um coeficiente " $\mathrm{K}$ " estimado em 0,5 (Figura 6).

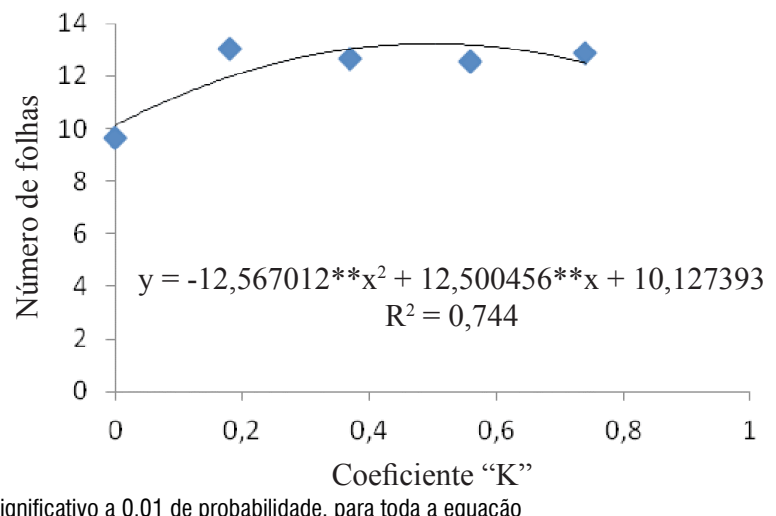

Figura 6. Número máximo de folhas em função dos coeficientes de transpiração, da bananeira Grande Naine

A análise de variância permitiu verificar o efeito significativo das lâminas de irrigação para a variável área foliar das plantas a partir do sexto mês até o décimo mês após o plantio porém os valores de área foliar foram reduzidos com a aproximação da época da colheita. Coelho et al. (2006b) avaliando o desempenho das cvs. Grande Naine e Prata-Anã, também encontraram efeito significativo de lâminas de irrigação para a área foliar.

O modelo quadrático apresentou o melhor ajuste matemático aos seis, oito e dez meses após o plantio e linear na colheita, para caracterizar a área foliar por planta em função das lâminas de irrigação aplicadas (Figura 7); tal acontecimento se justifica

A.

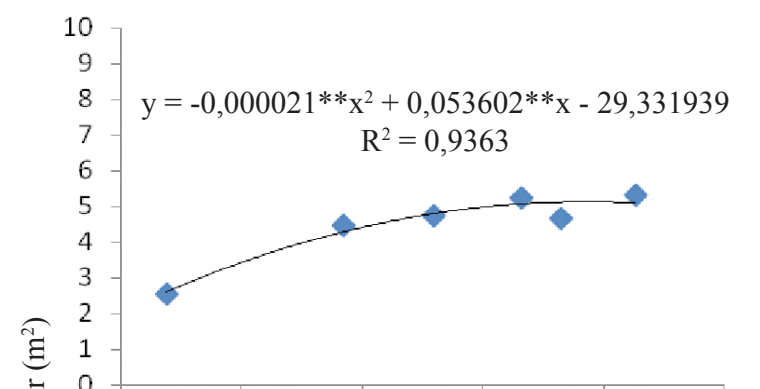

C.

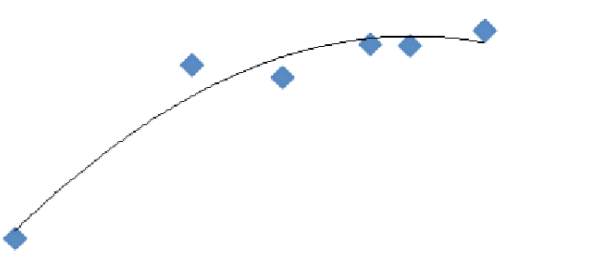

$y=-0,000050 * * x^{2}+0,127612 * * x-72,063927$ $\mathrm{R}^{2}=0,9427$ pelo fato de que, a partir da floração não há emissão de folhas as quais diminuem em número até a colheita por processo natural de queda foliar e desfolhas realizadas para controlar a infestação da Sigatoka amarela. O maior valor de área foliar $\left(9,35 \mathrm{~m}^{2}\right)$ foi obtido aos dez meses após o plantio com uma lâmina de

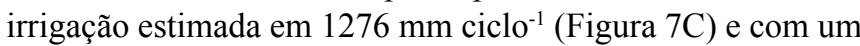
coeficiente "K" estimado em 0,57 (Figura 8).

Marques et al. (2011) encontraram, avaliando características agronômicas de bananeira tipo Prata em três ciclos produtivos, valores máximos de área foliar em torno de 9,75 e 11,70 m² para as cvs. Prata-Anã e PA 42-44, respectivamente, valores próximos aos encontrados no presente trabalho.

Segundo Taiz \& Zeiger (2009) os principais mecanismos de defesa da planta ao déficit hídrico no solo são a inibição da expansão foliar, a expansão do sistema radicular, o fechamento estomático e a aceleração da senescência e abscisão das folhas justificando o fato das plantas que receberam menor quantidade de água apresentar os menores valores para número de folhas e área foliar (Figuras 6 e 7).

O número de dias do plantio à floração, da floração à colheita e do plantio à colheita, não foi influenciado pelas lâminas de irrigação (Tabela 2); entretanto se observa, em valores absolutos, uma amplitude entre os tratamentos de 23 dias para o período entre o plantio e a floração, 8 dias para o período entre a floração e a colheita e 18 dias para o período entre o plantio e a colheita (Figura 9).

Os resultados do presente trabalho apresentaram uma redução no tempo para floração quanto aos resultados encontrados por Ramos et al. (2009) para a mesma cultivar, avaliando o desempenho de quatro grupos genômicos, ou seja, um valor de 429 dias para este caráter. Valores menores foram

B.

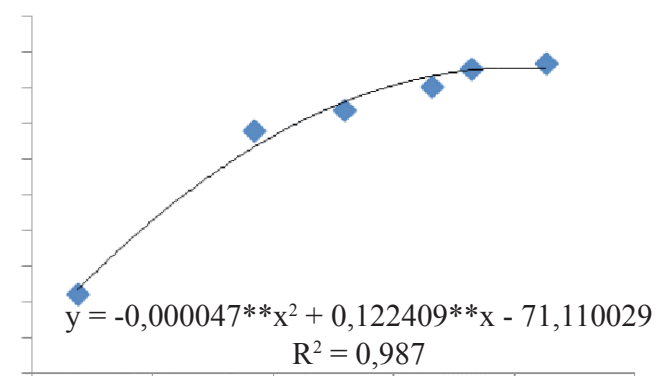

D.

$\mathrm{y}=0,005037 * * \mathrm{x}-1,053284$ $\mathrm{R}^{2}=0,9303$
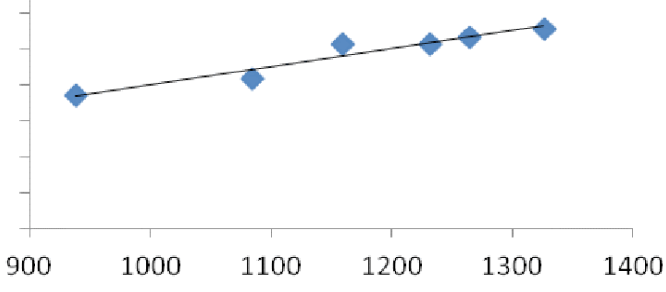

Lâminas de água ( $\mathrm{mm})$

* $e^{* *}$ significativo a 0,05 e 0,01 de probabilidade, para toda a equação

Figura 7. Área foliar da cv. de bananeira Grande Naine em função das lâminas de água aos seis, (A), oito (B) e dez meses após o plantio (C) e na colheita (D) 


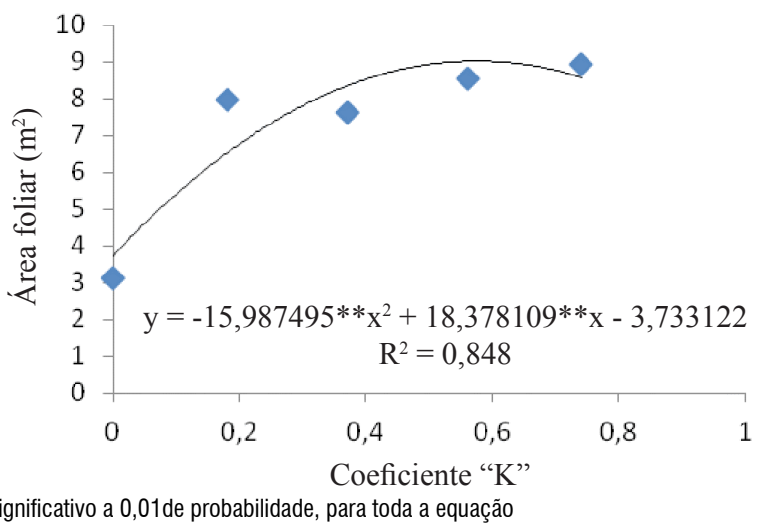

Figura 8. Área foliar máxima de bananeira Grande Naine em função dos coeficientes de transpiração, da bananeira Grande Naine

Tabela 2. Resumo da análise de variância e teste F do número de dias do plantio à floração (DPF), da floração à colheita (DFC) e do plantio à colheita (DPC) da cv. Grande Naine submetida a seis lâminas de irrigação no primeiro ciclo produtivo

\begin{tabular}{llll}
\hline \multicolumn{1}{c}{ FV } & DPF & DFC & DPC \\
Blocos & $2,190^{\star}$ & $1,315^{\text {ns }}$ & $5,253^{\star}$ \\
Lâminas & $1,648^{\text {ns }}$ & $2,400^{\text {ns }}$ & $9,849^{\text {ns }}$ \\
CV (\%) & 6,72 & 4,89 & 4,3 \\
Média (dias) & 273,49 & 111,16 & 382,20 \\
\hline
\end{tabular}

ns não significativo; * e ** significativo a 0,05 e 0,01 de probabilidade, respectivamente; CV - coeficiente de variação

encontrados por Silva et al. (2006) e Figueiredo et al. (2005), 249,87 e 229 dias, respectivamente, o primeiro avaliando clones de Cavendish e o segundo avaliando o efeito de diferentes lâminas de irrigação sobre a produtividade da bananeira (Musa sp. AAB) e sua influência sobre o período de floração e colheita no norte de Minas Gerais.

Todas as lâminas de irrigação aplicadas no presente estudo permitiram a redução do tempo entre o plantio e a floração (variando de 264 até 287 dias) tendo em vista que, segundo Borges \& Souza (2004) a bananeira Grande Naine possui um ciclo vegetativo (período do plantio até a floração) médio em torno de 290 dias.

O número de dias da floração à colheita variou de 109 para o tratamento L3 $\left(1159 \mathrm{~mm} \mathrm{ciclo}^{-1}\right)$ até 117 dias para

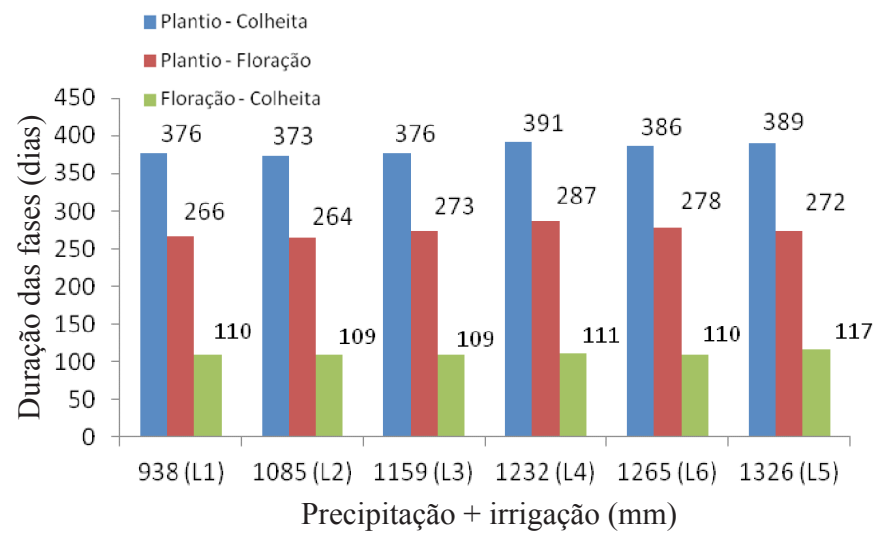

Figura 9. Duração das fases do ciclo da cultivar Grande Naine para as diferentes lâminas de irrigação o L5 (1326 mm ciclo-1) havendo, portanto, uma variação máxima de aproximadamente oito dias. Donato et al. (2006) encontraram, avaliando o comportamento de genótipos de bananeira no Sudoeste da Bahia, valor de 94,04 dias da floração à colheita da cv. Grande Naine. Silva et al. (2006) encontraram, avaliando clones de Cavendish, valor mínimo de 109,8 dias para a mesma cultivar resultado este muito próximo do encontrado neste trabalho. Figueiredo et al. (2005) observaram, avaliando o efeito de diferentes lâminas de irrigação, valor mínimo de 140 dias da floração à colheita, para a cv. Prata Anã. Valores maiores (154 dias) foram encontrados por Souza et al. (2011) quando avaliaram características de crescimento e produção de genótipos de bananeira em clima subtropical.

O ciclo total da cv. Grande Naine variou entre 373, para o tratamento L2 (1085 $\left.\mathrm{mm} \mathrm{ciclo}^{-1}\right)$ até 391 dias, para o L4 (1232 $\mathrm{mm} \mathrm{ciclo}^{-1}$ ) havendo uma variação máxima de aproximadamente 18 dias. Valores próximos foram verificados por Silva et al. (2004) ao encontrar valor mínimo de 357 dias para duração do ciclo da mesma variedade com uma lâmina de água de 2349,95 $\mathrm{mm}$ ciclo $^{-1}$. Flori et al. (2004) encontraram, avaliando o efeito do adensamento de plantas de bananeira Grande Naine, irrigadas no Submédio São Francisco, valor mínimo de 361 dias para duração do ciclo da cultura.

Apesar de não interferirem na duração do ciclo da cultura da bananeira, as lâminas de irrigação influenciaram o crescimento das plantas de tal forma que aquelas sujeitas ao manejo de irrigação utilizando o Kc (L6) apresentaram incrementos, em relação àquelas cujo manejo de irrigação utilizou coeficientes empíricos "K" (L1, L2, L3, L4 e L5), de 52,4; 8,0; 12,9; 5,1 e $5,5 \%$ para altura de plantas; de 45,$2 ; 9,1 ; 7,0 ; 2,4$ e $-0,1 \%$ para circunferência de pseudocaule; de 25,$3 ;-7,6 ;-4,9 ;-3,9$ e -6,3\% para número de folhas vivas e de 173,$5 ; 6,5 ; 11,7 ;-0,5$ e - $4,8 \%$ para área foliar, respectivamente, sinalizando que a utilização de coeficientes de transpiração para a estimativa da necessidade hídrica da cultura da bananeira é viável podendo ocorrer redução na quantidade de água aplicada e obter resultados semelhantes, como demonstrou o manejo de irrigação $\mathrm{L} 4(\mathrm{NH}=0,56 \mathrm{x} \mathrm{AF}$ $\mathrm{x}$ ETo), para a maioria das variáveis de crescimento estudadas. Ressalta-se que o valor obtido no presente estudo se manteve próximo do modelado por Coelho Filho et al. (2007) para a cultura do mamoeiro $(0,56)$ e superior ao das plantas de lima ácida 'Tahiti', manga, maçã e nogueira (Coelho Filho et al., 2004; Oliveira et al., 2009; Pereira et al., 2006) confirmando que a cultura da bananeira apresenta elevado consumo hídrico por unidade de área foliar, comparado com o das plantas arbóreas.

\section{Conclusões}

1. O crescimento das plantas da cv. Grande Naine foi influenciado pelas lâminas de água.

2. É possível e viável o manejo alternativo da irrigação utilizando-se dados de área foliar, evapotranspiração de referência e coeficientes empíricos para estimativa da necessidade hídrica da cultura.

3. O melhor desenvolvimento da cv. Grande Naine foi obtido com o coeficiente de transpiração, "K", de 0,57 e uma lâmina de irrigação estimada em $1247 \mathrm{~mm}_{\text {ciclo }}{ }^{-1}$. 


\section{Literatura Citada}

Allen, R. G.; Pereira, L. S.; Raes, D.; Smith, M. Crop evapotranspiration: guidelines for computing crop water requirements. Rome: FAO, 1998. 328p. Irrigation and Drainage Paper, 56.

Alves, A. A. C.; Silva Júnior, J. F. S.; Coelho, E. F. Estimation of banana leaf area by simple and non-destructive methods. In Congresso Brasileiro de Fisiologia Vegetal, 7, 2001, Fisiologia de plantas no novo Milênio: Desafios perspectivas, Ilhéus. Anais...Ilhéus: SBFV, 2001. CD-Rom

Alves, M. da S.; Coelho, E. F.; Paz, V. P. da S.; Andrade Neto, T. M. de. Crescimento e produtividade da bananeira cv. Grande Naine sob diferentes combinações de nitrato de cálcio e ureia. Revista Ceres, v.57, p.125-131, 2010.

Andrade, G. M.; Vasconcelos, L. F. L.; Veloso, M. E. da C.; Souza, V. A. B. de; Sousa, V. F. de. Avaliação de genótipos de bananeira no estado do Piauí: Comportamento vegetativo. In: Congresso Brasileiro de Fruticultura, 17, 2002, Belém. Anais... Belém: SBF, 2002. CD-Rom

Borges, A. L.; Souza, L. da S. O cultivo da bananeira. Cruz das Almas: Embrapa Mandioca e Fruticultura, 2004. 279p.

Braga Filho, J. R.; Nascimento, J. L. do; Naves, R. V.; Silva, L. B. e; Pereira, A. C. da C. P.; Gonçalves, H. M.; Rodrigues, C. Crescimento e desenvolvimento de cultivares de bananeira irrigadas. Revista Brasileira de Fruticultura. v.30, p.981988, 2008.

Coelho, E. F.; Costa, E. L. da; Ledo, C. A. da S.; Silva, S. de O. e; Produtividade e eficiência de uso de água das bananeiras 'Prata Anã' e 'Grand Naine' sob irrigação no terceiro ciclo no norte de Minas Gerais. Revista Irriga. v.11, p.460-468, $2006 \mathrm{a}$

Coelho, E. F.; Ledo, C. A. da S.; Silva, S. de O. e. Produtividade de bananeira 'Prata-Anã' e 'Grande Naine' no terceiro ciclo sob irrigação por microaspersão em tabuleiros costeiros da Bahia. Revista Brasileira de Fruticultura, v.28, p.435-438, 2006b.

Coelho Filho, M. A.; Angelocci, L. R.; Campeche, L. F. S. M.; Rojas, J. S. D.; Folegatti, M. V. Relações entre transpiração máxima, área foliar e evapotranspiração de referência em pomar jovem de lima ácida 'Tahiti'(Citrus latifolia Tan.). Revista Brasileira de Agrometeorologia, v.12, p.265-274, 2004.

Coelho Filho, M. A.; Coelho, E F.; Cruz, L. L. Uso da transpiração máxima de mamoeiro para o manejo de irrigação por gotejamento em regiões úmidas e sub-úmidas. Cruz das Almas: Embrapa Mandioca e Fruticultura Tropical, 2007. Documento 162

Costa, S. C.; Soares, A. A.; Sediyama, G. C.; Viana, T. V. de A.; Moreira, F. V. de O. Comportamento dos parâmetros indicativos de produção da bananeira pacovan submetida a diferentes lâminas de irrigação e doses de potássio na Chapada do Apodi - Limoeiro do Norte, CE. Mossoró, RN. Revista Caatinga, v.22, p.46-52, 2009.

D'Angiolella, G. L. B.; Castro Neto, M. T. de; Coelho, E. F. Tendências climáticas para os tabuleiros costeiros da região de Cruz das Almas, Bahia. Revista Bahia Agrícola, v.4, p.14-16, 2000.
Donato, S. L. R.; Silva, S. de O. e; Lucca Filho, O. A.; Lima, M. B.; Domingues, H.; Alves, J. da S. Comportamento de variedades e híbridos de bananeira (Musa spp.), em dois ciclos de produção no sudoeste da Bahia. Revista Brasileira de Fruticultura, v.28, p.139-144, 2006.

Doorenbos, J.; Kassam, A. H. Efeito da água no rendimento das culturas. Campina Grande: UFPB 1994. 306p. FAO. Irrigação e Drenagem 33.

Ferreira, D. F. SISVAR: Um programa para análises e ensino de estatística. Revista Científica Symposium, v.6, p.36-41, 2008.

Figueiredo, F. P. de; Oliveira, F. G.; Pereira, M. C. T. Efeito de diferentes lâminas de irrigação na produtividade da bananeira 'Prata Anã' cultivada no norte de Minas Gerais. Revista Ceres, v.52, p.429-433, 2005.

Flori, J. E.; Resende, G. M. de; Paiva, L. E. Produção de bananeira 'Grande Naine' superadensada e irrigada no vale do São Francisco. Ciência e Agrotecnologia, v.28, p.10601065, 2004.

Leite, J. B. V.; Rosa, I. de S.; Ramos, J. V.; Fraife Filho, G. de A.; Sacramento, C. K. do; Lins, R. D. Comportamento da bananeira cv. Grande Naine no sul do estado da Bahia. Revista Magistra, v.15, p.19-22, 2003.

Marques, P. R. R.; Donato, S. L. R.; Pereira, M. C. T.; Coelho, E. F.; Arantes, A. de M. Características agronômicas de bananeiras tipo Prata sob diferentes sistemas de irrigação. Pesquisa Agropecuária Brasileira, v.46, p.852-859, 2011.

Oliveira, G. X. S.; Coelho Filho, M. A.; Pereira, F. A. de C.; Coelho, E. F.; Paz, V. P. da S.; Castro Neto, M. T. de. Relações entre transpiração máxima, evapotranspiração de referência e área foliar em quatro variedades de mangueira. Revista Brasileira de Fruticultura, v.31, p.20-27, 2009.

Pereira, A. R.; Green, S.; Villa Nova, N. A. Penman-Monteith reference evapotranspiration adapted to estimate irrigated tree transpiration. Agricultural Water Management, v.83, p.153-161, 2006.

Ramos, D. P.; Leonel, S.; Mischan, M. M.; Damatto Júnior, E. R. Avaliação de genótipos de bananeira em Botucatu-SP. Revista Brasileira de Fruticultura, v.31, p.1092-1101, 2009.

Rodrigues, M. G. V.; Dias, M. S. C.; Pacheco, D. D. Influência de diferentes níveis de desfolha na produção e qualidade de frutos da bananeira 'Prata Anã'. Revista Brasileira de Fruticultura, v.31, p.755-762, 2009.

Silva, L. B.; Nascimento, J. L. do; Naves, R. V.; Ferreira, P. H. Comportamento vegetativo de cultivares de banana sob diferentes lâminas de irrigação. Pesquisa Agropecuária Tropical, v.34, p.93-98, 2004.

Silva, S. de O. e; Passos, A. R.; Donato, S. L. R.; Salomão, L. C. C.; Pereira, L. V.; Rodrigues, M. G. V.; Lima Neto, F. P.; Lima, M. B. Avaliação de genótipos de bananeira em diferentes ambientes. Ciência e Agrotecnologia, v.27, p.737-748, 2003.

Silva, S. de O. e; Pires, E. T.; Pestana, R. K. N.; Alves, J. da S.; Silveira, D. de C. Avaliação de clones de banana Cavendish. Ciência e Agrotecnologia, v.30, p.832-837, 2006.

Silva, S. de O. e; Rocha, S. A.; Alves, E. J.; Credico, M.; Passos, A. R. Caracterização morfológica e avaliação de cultivares e híbridos de bananeira. Revista Brasileira de Fruticultura, v.22, p.161-169, 2000. 
Souza, L. da S.; Souza, L. D. Caracterização físico-hidrica de solos da área do Centro Nacional de Pesquisa de Mandioca e Fruticultura Tropical, Cruz das Almas, Bahia. Cruz das Almas: Embrapa CNPMF, 2001. 56p. Boletim de Pesquisa, 20.
Souza, M. E. de; Leonel, S.; Fragoso, A. M. Crescimento e produção de genótiposde bananeiras em clima subtropical. Ciência Rural, v.41, p.587-591, 2011.

Taiz, L.; Zeiger, E. Fisiologia vegetal. 4.ed. Porto Alegre: Artmed, 2009. 848p. 